\title{
ANÁLISE MICROBIOLÓGICA DE RESÍDUO SUÍNO PARA AVALIAÇÃO DE BIORREMEDIAÇÃO E BIODIVERSIDADE
}

\author{
A MICROBIOLOGICAL ANALYSIS OF PORK RESIDUES \\ FOR BIOREMEDIATION AND BIODIVERSITY EVALUATION
}

\author{
Flávia V. B. Wiecheteck ${ }^{1}$, Inara Biscaia ${ }^{1}$, Melian L. Scherer ${ }^{1}$, \\ Raquel Gelinski ${ }^{1}$,Tarcila Bueno ${ }^{1}$, Zoli Catarina Zacharias Oliveira ${ }^{2}$, \\ Marcos Pileggi² \\ 1 Universidade Estadual de Ponta Grossa, Campus em Uvaranas, Curso de Engenharia \\ de Alimentos, Ponta Grossa, Paraná, Brasil. \\ 2 Autor para contato: Universidade Estadual de Ponta Grossa - UEPG, Campus em \\ Uvaranas, Departamento de Biologia Estrutural, Molecular e Genética, \\ Ponta Grossa, PR, Brasil; (42) 220-3734; e-mail: mpileggi@onda.com.br, \\ mpileggi@uepg.br
}

Recebido para publicação em 31/03/2003

Aceito para publicação em 12/03/2004

\section{RESUMO}

A preocupação com o meio ambiente vem crescendo com o passar dos anos. Várias empresas surgem e conseqüentemente, resíduos são criados e novas soluções devem ser achadas para tentar reduzir esse problema ambiental. Este projeto tem por objetivo estudar através de análises microbiológicas os resíduos não aproveitados da industrialização suína (banha, pêlo, sangue, fezes, urina, águas residuárias). Os meios utilizados para aplicações das amostras foram: Agar Nutriente, Agar Sangue, MacConkey, Sabouraud e Ágar Nutriente com Tioglicolato, sendo que a incubação das placas e dos tubos se deu por 20 horas em estufa a $37^{\circ} \mathrm{C}$, exceto o meio com Tioglicolato, que também foi incubado a $30 \pm 2^{\circ} \mathrm{C}$. Os resultados mostraram diferentes tipos de contaminantes nos resíduos, como fungos, enterobactérias e bactérias anaeróbicas, mas em uma baixa diversidade. Uma explicação razoável para isso seria que esses resíduos, devido a suas propriedades físico-químicas, seriam extremamente seletivos para o crescimento de microrganismos, mas as espécies que conseguissem se desenvolver seriam opções interessantes para realizar a biorremediação desses resíduos.

Palavras-chave: resíduos suínos; indústria alimentícia; microbiologia; biorremediação 


\begin{abstract}
Public awarenesess of environmental problems has been gradually increasing along the years. Companies arise, and thus residues are created, which brings up an urge solutions for this kind of environmental problem. This research intends to study pork industry residues (fat, hair, faeces, urine, washing water) by means of microbiological analyses. The media used were Nutrient Agar, Mac Conkey Agar, Sabourand Agar and Tioglicolate Nutrient Agar, which were incubated for 20 hours at $37^{\circ} \mathrm{C}$, with the exception of the Tioglicolate medium, that was incubated for 20 hours at $30 \pm 2^{\circ} \mathrm{C}$. Some different kinds of microbiological contamination, such as fungi, enteric and anaerobic bacteria were found, but in a low degree of biodiversity. We believe that a reasonable explanation for this is that pork residues, due to their physicochemical characteristics, are a very selective environment for microbiological growth, but the species that are able to thrive in it could be a good source of bioremedial organisms.
\end{abstract}

Key words: pork residues; food industry; microbiology; bioremediation

\section{Introdução}

A biossegurança é o conjunto de ações voltadas para a prevenção, minimização ou eliminação de riscos inerentes às atividades de pesquisa, produção, desenvolvimento tecnológico e prestação de serviços, visando à saúde do homem, dos animais, a preservação do meio ambiente e a qualidade dos resultados (Teixeira; Valle, 1996).

A biossegurança, particularmente a microbiológica, é um fator fundamental na atividade produtiva atualmente de produtos manufaturados. Sua manutenção e avaliação são itens que demandam tecnologias mais acuradas, frente a crescente exigência por parâmetros de segurança. Já a biodiversidade microbiológica constitui um parâmetro cuja manutenção em altos índices indicam uma menor agressão ao meio ambiente por uma determinada atividade produtiva.

Biorremediação pode ser definida como uma tecnologia de utilização de microrganismos na recuperação de áreas degradadas pela disposição de resíduos. É praticada de modo a promover as melhores condições ambientais para o desenvolvimento da capacidade metabólica dos microrga- nismos em questão, descontaminando áreas através de meios orgânicos e biológicos. A técnica consiste na aplicação de processos de biodegradação no tratamento de resíduos para recuperar e regenerar ambientes que sofreram impactos negativos, mantendo o equilíbrio biológico dos ecossistemas. Ela atua por meio da introdução de processos biológicos adicionais para a decomposição dos resíduos que favorecem e incrementam a velocidade do processo natural de degradação (Biodiversidade, 2003 b).

Muitos esforços têm sido empreendidos no desenvolvimento de sistemas que diminuam ou controlem a poluição das águas e dos solos. O manejo adequado de diversos ecossistemas, com o emprego correto das tecnologias disponíveis de biotratamento e biorremediação, é realidade inclusive nos países em desenvolvimento (Biodiversidade, 2003 a).

O risco anual que uma perturbação temporária da microbiota intestinal, resultante de uma infecção por certos enteropatógenos, como Salmonella spp., está calculado em 1 em 45 milhões. Concluiu-se que os riscos microbiológicos dos resíduos gerados pela indústria de derivados suínos são importantes, apesar 
de menores que os riscos da presença do antibiótico tetraciclina na carne destes animais, sendo assim, tanto o controle microbiológico como o de antibióticos devem ter prioridade (Berends et al., 2001).

No ecossistema global, a decomposição da matéria orgânica poluente, originada da atividade antrópica, em dióxido de carbono e água, pode ser atualmente estimulada pela utilização de métodos que otimizem a biodegradação microbiana (Biodiversidade, 2003 a).

O objetivo deste trabalho foi avaliar a qualidade microbiológica do resíduo de origem suína de uma indústria alimentícia da cidade de Ponta Grossa, Paraná, por meio de incubação em meios de cultura específicos e contagem. De acordo com o nível de segurança destes resíduos, novas possibilidades de utilização poderiam ser aventadas, contribuindo para um melhor custo-benefício da indústria e diminuindo os impactos ambientais na região. Como há poucos artigos publicados com esta abordagem, este trabalho procura levantar dados preliminares sobre a biorremediação de compostos de origem suína.

\section{Materiais e Métodos}

Utilizou-se amostras de resíduos suínos coletadas diretamente de um reservatório, com o auxílio de um "swab" e diluídas em tubos de ensaio assépticos de $10 \mathrm{~mL}$ de capacidade com $1 \mathrm{~mL}$ de solução salina a 0,9\% Em seguida foram inoculadas em placas de cultura contendo $25 \mathrm{~mL}$ de meio Agar nutriente, Agar sangue, Sabouraud, MacConkey e em 8 tubos com meio líquido de Tioglicolato. As placas e 4 tubos foram incubados em estufa a $37^{\circ} \mathrm{C}$ por 20 horas, os outros 4 tubos ficaram expostos à temperatura de $30^{\circ} \mathrm{C}$.

Para a preparação do Agar Sangue, utilizouse Agar nutritivo e adicionou-se cerca de 7,5\% de sangue de carneiro desfibrinado.

\section{Resultados}

Resultados obtidos após 20 horas de incubação encontram-se no Quadro 1.

Quadro 1 - Análise microbiológica do desenvolvimento nos meios de cultura

\begin{tabular}{|c|c|c|c|}
\hline Meio & $\mathbf{N}^{\circ}$ de colônias & $\mathbf{N}^{\circ}$ de colônias & Características \\
\hline Ágar Sangue & 100 & 90 & $\begin{array}{c}\text { Colônias de coloração } \\
\text { cinza esverdeadas e } \\
\text { formato circular, tipo } \\
\text { Staphylococcus }\end{array}$ \\
\hline Agar & (placa 2) & Colônias brancas e \\
vacConkey & 98 & 63 & $\begin{array}{c}\text { vermelhas sendo a } \\
\text { maioria vermelhas, } \\
\text { tamanhos uniformes, } \\
\text { distribuídas em } \\
\text { toda placa. }\end{array}$ \\
\hline Agar Sabouraud & (placa 2) & & $\begin{array}{c}\text { Colônias brancas de } \\
\text { tamanhos uniformes }\end{array}$ \\
\hline $\begin{array}{c}\text { Agar } \\
\text { nutriente }\end{array}$ & $\begin{array}{c}300 \\
\text { (placa 1) }\end{array}$ & $\begin{array}{c}\text { Colônias brancas de } \\
\text { tamanhos variados }\end{array}$ \\
\hline
\end{tabular}


Na análise microbiológica do desenvolvimento no meio de cultura anaeróbico usandoTioglicolato, houve crescimento de microorganismos nas temperaturas de 30 e $37^{\circ} \mathrm{C}$.

\section{Discussão}

A utilização dos meios de cultura: Agar nutriente, Agar Sabouraud, MacConkey, Agar sangue e tioglicolato, foi adequada para avaliar os índices de biodiversidade e biossegurança dos resíduos da indústria alimentícia de produtos derivados de suínos.

Na maioria das placas houve uma grande proliferação bacteriana, ao contrário do observado para fungos. Nos tubos com meio líquido com Tioglicolato houve crescimento de bactérias anaeróbicas, tanto incubadas a $37^{\circ} \mathrm{C}$ quanto à temperatura ambiente, mostrando a capacidade de degradação do material por esta microbiota em diferentes condições ambientais, característica importante para biorremediação. A suplementação do Agar nutriente com o tioglicolato de sódio, poderia permitir que até microorganismos mais restritos como o Clostridium tetani se desenvolvessem.

A utilização do Agar Sangue seria interessante para se detectar bactérias patogênicas hemolíticas, porém neste caso elas não foram encontradas.

O Ágar Nutriente, sendo um meio rico, permitiu o desenvolvimento de bactérias e leveduras, para uma avaliação do índice de colonização e de biodiversidade encontrado nos resíduos. Assim, detectou-se mais de 200 ufc/placa, em média, mas apresentando uma baixa diversidade morfológica, indicando a alta especificidade em termos de nicho ecológico dos resíduos. Em termos de biorremediação, esta pode ser uma característica facilitadora, já que existem poucos tipos de microrganismos a serem modificados.

A família Enterobacteriaceae foi identificada, inferindo a presença de coliformes fecais e totais, bioindicadores de poluição fecal.

A presença dos fungos no meio Sabouraud é um indicador importante para a possível degradação do resíduo, pois estes microrganismos possuem uma alta capacidade de metabolismo e amplo espectro de tolerância a fatores ambientais diversos. Alguns podem ser patogênicos, mostrando a necessidade de aplicação um sistema de identificação dos mesmos.

\section{Conclusões}

O tamanho e a diversidade da microbiota no estudo de resíduos suínos, junto com a interação com outros microorganismos existentes no meio ambiente, propõe um problema real em qualquer tentativa de avaliar o papel daqueles na degradabilidade e biossegurança do resíduo gerado. Desta forma, nosso estudo se propôs a conhecer, em uma primeira abordagem, grupos de microorganismos existentes no resíduo suíno, indicadores de contaminação fecal e biodegradação.

A escolha de meios seletivos para fungos e enterobactérias, além de meios ricos, com ou sem a adição de ágar e de tioglicolato, procurou levantar a gama de microrganismos que colonizam este tipo de resíduo. Os resultados demonstraram uma baixa diversidade, sugerindo que o material seja muito seletivo. A presença de fungos filamentosos e leveduras demonstra a possibilidade da utilização como biodecompositores, e eventualmente como soluções biotecnológicas no tratamento de resíduos industriais. Não foram encontradas bactérias hemolíticas, que neste caso poderiam ser consideradas como patogênicas. Em relação à presença tanto de microorganismos aeróbicos quanto anaeróbicos, também se demonstra a possibilidade de biorremediação em diferentes condições fisiológicas.

Sobre as enterobactérias, a presença de pequenos bastonetes retos gram-negativos não serviu à elucidação diagnóstica, pois é um caráter comum a várias espécies. O comportamento bioquímico dessas amostras e uma posterior caracterização bioquímica permitiria a identificação destes microrganismos.

Análises físico-químicas e microbiológicas dos resíduos da indústria alimentícia de suínos, em dife- 
rentes etapas de industrialização de seus derivados, além de buscar a presença de antibióticos e a identificação de gêneros de fungos e bactérias, podem levar a concepção de estratégias biotecnológicas na utilização destes resíduos. Da mesma forma, técnicas quantitativas mais acuradas deverão ser implementadas, para uma melhor caracterização da microbiota colonizadora deste tipo de resíduo.

\section{REFERÊNCIAS}

BERENDS, B.R.; van den BOGAARD, A.E.; van KNAPEN, F.; SNIJDERS, JM. Human health hazards associated with the administration of antimicrobials to slaughter animals. Part I. An assessment of the risks of residues of tetracyclines in pork. Veterinary Quarterly, v.23, n.1 , p.2-10, Jan. 2001. TEIXEIRA, P.; VALLE, S. Biossegurança: uma abordagem multidisciplinar. Rio de Janeiro: Fiocruz, 1996.

BIODIVERSIDADE: perspectivas e oportunidades tecnológicas. Disponível em: <http://www.bdt.fat.org.br/ publicacoes/padct/bio/cap9/3/rosbio2.html>. Acesso em: 02 maio 2003. (a).

BIODIVERSIDADE. Disponível em: <http://

www.brasworld.com.br/portugues/assesoria_ambiental/ biotecnologia/bitecnologia.html>. Acesso em: 06 maio 2003. (b). 